\title{
PROPOSTA DE MODELO DE GESTÃO COM FRONTEIRAS EXPANDIDAS: DECISÕES HIERAQUIZADAS BASEADAS NA RECONFIGURAÇÃO ORGANIZACIONAL POR PROCESSO
}

\section{HIERARQUIZATION OF DECISIONS IN ORGANIZATION : PROPOSAL OF THE SHARING MANAGEMENT MODEL}

\author{
Takeshy Tachizawa ${ }^{1}$; Hamilton Pozo $^{2}$ \\ ${ }^{1}$ Faculdade Campo Limpo Paulista - FACCAMP - Campo Limpo Paulista - Brasil \\ usptakes@uol.com.br \\ ${ }^{2}$ Faculdade Campo Limpo Paulista - FACCAMP - Campo Limpo Paulista - Brasil \\ hprbrazil@hpotmail.com
}

\begin{abstract}
Resumo
O artigo procura apresentar um modelo de gestão em rede, de serviços compartilhados em tecnologias da informação. Adotou-se a metodologia de estudo de caso a partir da aplicação do constructo em uma empresa de construção civil. O modelo de gestão permitiu agrupar empresas em regime de trabalho colaborativo. A concepção do constructo abrangeu a implementação de um regime de parceria na forma de um pool de organizações para criação de uma central de serviços de informática. Entre os resultados obtidos pela adoção do modelo proposto destacam-se o compartilhamento de serviços comuns e a obtenção de economia de escala na potencial implementação de tecnologias da informação nas organizações.
\end{abstract}

Palavras-chave: cadeia produtiva expandida; compartilhamento de tecnologias da informação e comunicação; modelo de gestão em rede; hierarquização de decisões.

\section{Introdução}

As mudanças observadas nas práticas de gestão das organizações, em especial daquelas consideradas modernas, estão se revelando contraditórias, evidenciando determinados questionamentos quanto aos seus métodos e pressupostos gerenciais (TACHIZAWA, 2010). Isso por muitas décadas tem pautado a gestão das organizações sob a denominação mais freqüente de modelo clássico-burocrático, fundamentado essencialmente na separação entre planejamento e execução e na divisão do trabalho por especialização funcional, ou seja, gestão por funções.

Tais práticas tinham-se constituído em ações instrumentais da preservação do modo típico da era industrial que se voltavam às operações e controle dos ativos tangíveis (GOREY; DOBAT, 
1996), pouco eficazes para as novas demandas da era do conhecimento.

Em decorrência da aceleração do intercâmbio comercial e tecnológico ocorrida nos últimos anos, tanto em nível interno de cada país como, principalmente, no plano da economia internacional, as organizações viram-se obrigadas a promover mudanças.

Isso, sob pena de serem deslocadas do mercado, e foram abrindo mão de práticas tradicionais que com o passar do tempo acabaram se tornando verdadeiros descaminhos em seus anseios de desenvolvimento, na medida em que sua utilização passava a produzir resultados indesejáveis tanto em desempenho quanto em qualidade.

A não participação do pessoal envolvido na execução operacional em atividades de planejamento prejudicava a qualidade do mesmo, além de criar insatisfação naquele pessoal. Por sua vez, a divisão de trabalho excessivamente fragmentada, visando ganhos em economia de escala, não apenas deixava de alcançar tais ganhos como tornava difícil de suportar por tempo maior um trabalho limitado (TACHIZAWA, 2010).

Para sair de tais tipos de impasses, muitas organizações foram introduzindo experiências na maneira de alocar responsabilidades, distribuir funções e gerenciar as atividades de seus integrantes. Outras, na busca de uma maior flexibilidade organizacional, adotaram formas de organização do tipo, em rede, virtual, auto-desenhado, modelo inteligente, adhocrática, organização holística e afins.

Entre tais modelos, e adotado no presente trabalho, destaca-se a o enfoque da reconfiguração organizacional em torno de processos.

Com base nessa abordagem, foi possível delinear uma proposta de modelo de gestão, com ênfase no uso estratégico das tecnologias da informação, contemplando:

- meio ambiente e seus elementos estratégicos;

- interação permanente com o mercado e clientes;

- estruturação das atividades por processos;

- parcerias e terceirização;

- aplicação dos recursos das tecnologias da informação.

No modelo concebido para a organização, com fronteiras ampliadas, considerou-se a possibilidade de reduzir a necessidade de processar informações no contexto do planejamento dos investimentos em tecnologias da informação - TI (GALBRAITH, 1987). E visando, ainda, otimizar o uso das TI, foi adotado neste trabalho, o embasamento conceitual e de técnicas (TACHIZAWA; SCAICO, 2006), que propiciaram suporte ao modelo proposto, conforme explicitado a seguir.

\section{Fundamentação teórica}




\subsection{Ambiente externo e seus elementos estratégicos}

O meio ambiente, no qual se inserem as empresas da economia nacional, é o ponto de partida do modelo de organização com fronteiras expandidas, uma vez que metodologicamente parte-se de 'fora-para-dentro' segundo o enfoque sistêmico (TACHIZAWA, 2010), que serviu de fundamento filosófico ao modelo proposto.

É no contexto externo à empresa que ocorrem as mutações ambientais que ditam a interrupção ou continuidade, na vida das organizações. A organização com fronteiras expandidas se apóia na estrutura por processos, procura estabelecer uma estrutura interna enxuta para a mesma, de forma a torná-la ágil para enfrentar e se adaptar aos eventos externos, não-controláveis pela empresa.

As variáveis ambientais que definem a missão, a visão, os contornos da organização bem como os elementos estratégicos genéricos da organização, foram os fatores de identificação dos processos-chave, de forma destacada dos demais processos sistêmicos conforme aplicado no estudo de caso.

A organização esperada no contexto de um cenário realista, face às mudanças que estão ocorrendo no mercado é descrita no tópico 6 deste trabalho, no que se pode chamar de modelo de organização com fronteiras expandidas, baseada em uma estrutura por processos.

\subsection{Interação com o mercado}

Neste modelo de organização com fronteiras expandidas (TACHIZAWA; SCAICO, 2006), ganha destaque a função de atendimento a clientes, que se constitui em elemento comum, qualquer que seja o tipo de organização. Ou seja, independente do ramo de negócios no qual a organização esteja inserida, algumas características genéricas são necessárias de serem internalizadas em seus processos sistêmicos.

Suas atividades básicas seriam a de desenvolver atividades de identificação das necessidades dos clientes, transformando-as em requisitos de qualidade para os produtos fornecidos pela empresa, bem como identificar e desenvolver novos produtos.

Desenvolveria, também, todo trabalho de interação com os clientes e fornecedores visando comunicar os aperfeiçoamentos na estrutura, organização e processos da empresa, que visem aprimorar o atendimento e relacionamento com estes públicos. Este trabalho contribuiria positivamente para a criação e consolidação de traços de imagem desejáveis à empresa (próatividade, dinamismo e flexibilidade).

A proposta do modelo é que o relacionamento da organização com seus clientes e seus fornecedores seja orientado pelo pressuposto da satisfação das necessidades de seus diferentes 
públicos. Ou seja, de um lado significa a antecipação das necessidades do cliente e assegurar a qualidade dos serviços prestados.

De outro lado, junto às suas fontes de fornecimento de insumos produtivos, significa garantir que as ações se direcionem no sentido do desenvolvimento dos fornecedores de modo que os mesmos atuem como parte integrante da cadeia de agregação de valores voltada à satisfação total de seus públicos de interesse (stakeholders).

Tais fundamentos teóricos subsidiaram a estruturação da organização por processos, conforme contornos delineados no tópico 7.

\subsection{Estruturação das atividades por processos}

A organização com fronteiras expandidas (TACHIZAWA; SCAICO, 2006), pressupõe uma estrutura interna ágil que assegure a continuidade das conquistas obtidas junto ao mercado. Enquanto que no plano externo a organização tem que ser eficaz obtendo resultados econômicos favoráveis, internamente há necessidade de uma infra-estrutura de gestão que promova a convergência de suas ações de forma coerente com as mutações ambientais.

Esta infra-estrutura gerencial (não abrange, portanto, outros elementos como tecnologias aplicadas a produtos, a processos e correlatos) é constituída pelos recursos internos da organização, representados na forma de: estrutura organizacional; recursos humanos; sistemas e tecnologias da informação e de comunicação; e processos sistêmicos (GONÇALVES e RICCIO, 2009). A maneira proposta (vide tópico 7) para identificação do que é essencial na organização e do que é acessório, foi através da hierarquização dos processos sistêmicos, particularmente aqueles considerados produtivos.

\subsection{Parcerias e terceirização}

Como subcontratação, parceria e terceirização, para efeito deste trabalho, significou aproveitar as possibilidades e a capacidade da organização de estabelecer parcerias, tanto "para-afrente' junto aos clientes como de forma reversa junto aos fornecedores (TACHIZAWA; SCAICO, 2006). Tais 'parcerias' constituem uma alternativa à possibilidade de integração vertical da organização, onde a mesma detém completo domínio das fontes de suprimento de insumos produtivos ou de canais de comercialização junto aos consumidores finais/clientes.

Em relação às 'parcerias', o que o modelo de organização com fronteiras expandidas sugere, é adotar a subcontratação externa de atividades em direção aos fornecedores da empresa. Para frente, de forma análoga, recomenda-se concretizar parcerias com empresas e entidades externas, no sentido de que as mesmas complementem as atuais atividades desenvolvidas internamente pela 
empresa visando o atendimento aos clientes. A maior ou menor possibilidade de integração irá depender do tipo de ramo de negócios no qual a organização estiver inserida. Conforme já evidenciado anteriormente, a linha estratégica possível de ser adotada está calcada em uma flexibilidade operacional de um modelo de gestão centrado nas atividades essenciais - processos produtivos - consideradas permanentes na organização com fronteiras expandidas (TACHIZAWA; SCAICO, 2006), ao lado das atividades acessórias - processos de apoio - a serem subcontratadas

junto ao mercado. É o modelo adotado de criação de um pool de empresas congêneres para desenvolvimento de atividades comuns a todas (tópico 7.1.).

A vantagem para a empresa seria minimizar as naturais oscilações do volume de trabalho em função da maior ou menor demanda pelos serviços prestados aos clientes.

Outro ponto positivo é que a organização com fronteiras expandidas poderia se concentrar naquilo que faz bem e contratando de fora, o que outras empresas especializadas fazem melhor do que ela própria.

É em função desta especialização que os fornecedores podem executar os trabalhos subcontratados melhor e a um custo comparativamente menor do que se fosse realizado internamente.

Neste modelo, poder-se-ia adotar esquemas de parceria com empresas fornecedoras de mãode-obra e com organizações de serviços especializados na área de treinamento, desenvolvimento de recursos humanos, administração de serviços condominiais, serviços de digitação, de suporte em tecnologias da informação, de pesquisas de mercado, e outros serviços correlatos.

Com a adoção do esquema de parcerias junto a clientes, a empresa tende a ampliar, virtualmente, suas fronteiras, na medida em que sistemicamente sua atuação se fará presente internamente às organizações que com ela interagem.

De forma inversa, as parcerias podem viabilizar o ingresso físico de fornecedores, e mesmo clientes intermediários, intra-organizacionalmente, de tal forma que as dependências da organização se transforme em locus onde se daria o fornecimento dos insumos produtivos (ou comercialização, no caso de clientes intermediários) por parte dos fornecedores, aos processos internos da empresa. Em outras palavras, é um contexto em que várias empresas fornecedoras (ou clientes) estariam trabalhando dentro da organização, integrada física e operacionalmente, preservando suas entidades jurídicas independentes.

\subsection{Recursos das tecnologias da Informação}

A utilização das tecnologias da informação na organização, como foi o caso da empresa objeto do estudo de caso, com fronteiras expandidas, pode resultar em benefícios internos e 
externos à mesma. No plano interno tem-se a ampliação da capacidade de processar informações, além daquela proporcionada pela própria conformação da estrutura organizacional. E, portanto, de ampliar o processo decisório, possibilitando com isso, a obtenção de estrutura horizontalizada, mais achatada, e com menor número de níveis hierárquicos. Isso pode resultar em menor necessidade de processar informações, conforme abordado no tópico 7.3.

$\mathrm{Na}$ organização com fronteiras expandidas tem-se a possibilidade de interagir, virtualmente, com seus fornecedores, com seus distribuidores e consumidores e, complementarmente, com entidades-parceiras em alianças estratégicas. Vem à tona, a possibilidade de utilização dos recursos do comércio e intercâmbio eletrônico de documentos (B2B, B2C e Internet) para fins de interação junto aos fornecedores, órgãos clientes e entidades/empresas parceiras da organização (ALBERTIN, 2009). Tal possibilidade amplia, virtualmente, as fronteiras da organização na medida em que a comunicação e relacionamento, se efetiva por meio eletrônico, com fornecedores, clientes, parceiros e demais entidades, viabilizando a conectividade interorganizacional no fluxo de documentos e informações (ALBERTIN, 2010).

\section{Metodologia da pesquisa}

O trabalho foi baseado no método do estudo de caso, pois se limita à investigação de um mesmo fenômeno em uma mesma organização, em um determinado período de tempo.

O estudo de caso, segundo Yin (2001) é um questionamento empírico que investiga um fenômeno contemporâneo com seus contornos delineados no mundo real, quando as fronteiras entre o fenômeno e contexto não são claramente evidentes, e nos quais múltiplas fontes de evidência são usadas. Considerando seu objetivo, este estudo caracterizou-se como exploratório e descritivo. É exploratório, pois sua principal finalidade foi desenvolver, esclarecer e modificar conceitos e idéias para a formulação de abordagens mais condizentes com o desenvolvimento de estudos posteriores. E é descritivo, uma vez que os autores procuraram descrever a realidade como ela é sem se preocupar em modificá-la (Gil, 1987; Selltiz et al., 1987).

Observando tais preceitos metodológicos, foi realizado um estudo de caso único, na Construtora S.A. que passava por significativas mudanças tecnológicas, estruturais e organizacionais. Entrevistas semi-estruturadas, observação de processos e análise documental foram os métodos de levantamento de dados adotados na formulação deste trabalho.

A técnica de entrevista, aplicada junto aos gestores e coordenadores, justificou-se por ser uma forma de levantamento de posição que conduz os entrevistados a exporem suas percepções a respeito das situações, fenômenos e problemas associados ao objeto de pesquisa mediante o diálogo com o entrevistador. Os entrevistados foram os coordenadores de produção e gestores das unidades 
produtivas da empresa, objeto do estudo de caso. Noventa e sete entrevistas semi-estruturadas foram aplicadas ao longo do ano de 2010, entre janeiro e setembro, que tiveram duração média de duas horas.

A análise de dados foi realizada de forma a agrupar os resultados por nível hierárquico na organização, o que garantiu um alinhamento de percepções por grupos de pessoas com perfis, características e responsabilidades semelhantes.

\section{Caracterização da empresa}

\subsection{A organização}

A Construtora S/A, pertence ao setor econômico da construção civil, que se caracteriza como uma indústria homogênea, em função do tipo de produto, com poucas empresas de elevado capital e escalas produtivas, convivendo com aquelas de baixo grau de concentração de capital (EXAME, 2010).

É um ramo de negócios com forte influência dos Órgãos Reguladores e do Governo, que através de suas políticas econômicas, afeta diretamente as pequenas e médias empresas do setor (TACHIZAWA, 2010).

Tal situação provoca instabilidade e alta variabilidade de cenários o que torna fundamental que qualquer estratégia competitiva a ser adotada pelas empresas do setor, leve em conta a necessidade de manter alto grau de flexibilidade e adaptabilidade em seu processo de gestão.

\subsection{Missão e serviços prestados}

A Construtora S/A tem por missão, a construção de edificações residenciais e comerciais. Seus principais clientes são organizações públicas e privadas, e o consumidor final para os produtos habitacionais. Seus produtos se caracterizam como sendo bens de consumo duráveis, voltados aos clientes comerciais e consumidores finais privados.

\subsection{As operações da empresa}

Ao lado das particularidades do macro-ambiente no qual se inserem as pequenas e médias empresas construtoras, encontra-se o caráter intermitente e itinerante próprio das atividades de construção civil habitacional, o que dificulta sobremaneira o desenvolvimento e modernização tecnológica. A dispersão espacial adicionada à variabilidade dos próprios processos sistêmicos, comprometiam a continuidade do fluxo de produção. Tais fatores geravam restrições para a obtenção de escala de produção, o que condiciona adversamente a alocação intensiva de tecnologia 
e capital fixo de longo prazo.

\subsection{Produtos e estratégias corporativas}

Complementarmente aos aspectos operacionais, tem-se a natureza intrínseca do produto habitacional como habitat que faz com que sejam susceptíveis à diferenciação inerente ao gosto pessoal do seu morador, acrescido da diversidade quanto à disponibilidade e característica do terreno e da legislação de uso e ocupação do solo, fatores estes que dificultam a padronização de projetos e dos produtos habitacionais.

Pode-se, com base nessa caracterização, deduzir um tipo de linha estratégica considerada intrínseca às empresas típicas do setor, e que se incorpora ao modelo de organização baseada em processos. Esta linha estratégica intrínseca, na forma adotada ao modelo de organização proposto, foi delineada em termos de regras de gestão direcionadas à gestão por processos.

\subsection{Contexto e mudanças organizacionais}

A Construtora SA, de médio porte, vivenciava um cenário de baixa lucratividade em face da crise econômica que o país atravessava. Isso exigia mudanças organizacionais visando perpetuar a organização no mercado. Esse contexto conjuntural afetava todas as empresas do setor de construção civil, notadamente as microempresas desse segmento da economia nacional.

A entidade de classe que congregava as microempresas do segmento, dada a necessidade de sobrevivência do setor econômico como um todo, sugeriu a criação de um órgão de serviços compartilhados diretamente vinculado a própria entidade patronal da construção civil.

Nesse momento, os dirigentes da Construtora SA vislumbraram uma oportunidade de não somente promover suas mudanças internas como também de contar com uma central de serviços compartilhados na forma de uma empresa independente e com personalidade jurídica própria.

Daí surgiu a idéia da Empresa de Serviços Compartilhados - ESC, na forma concebida no tópico explicitado a seguir.

\section{Proposta de modelo de gestão com cadeia de produção expandida}

O modelo de gestão proposto para a Construtora S. A., em nível externo, considerou a criação de uma organização de prestação de serviços compartilhados, mantida por um pool de micro e pequenas empresas do setor de construção civil (vide detalhes de concepção da Empresa de Serviços Compartilhados - ESC no tópico 7.1).

A ESC, em sua concepção e implementação, se apoiou na horizontalização da estrutura da Construtora SA, de forma coerente à sua nova reconfiguração por processos (vide figura 01). 


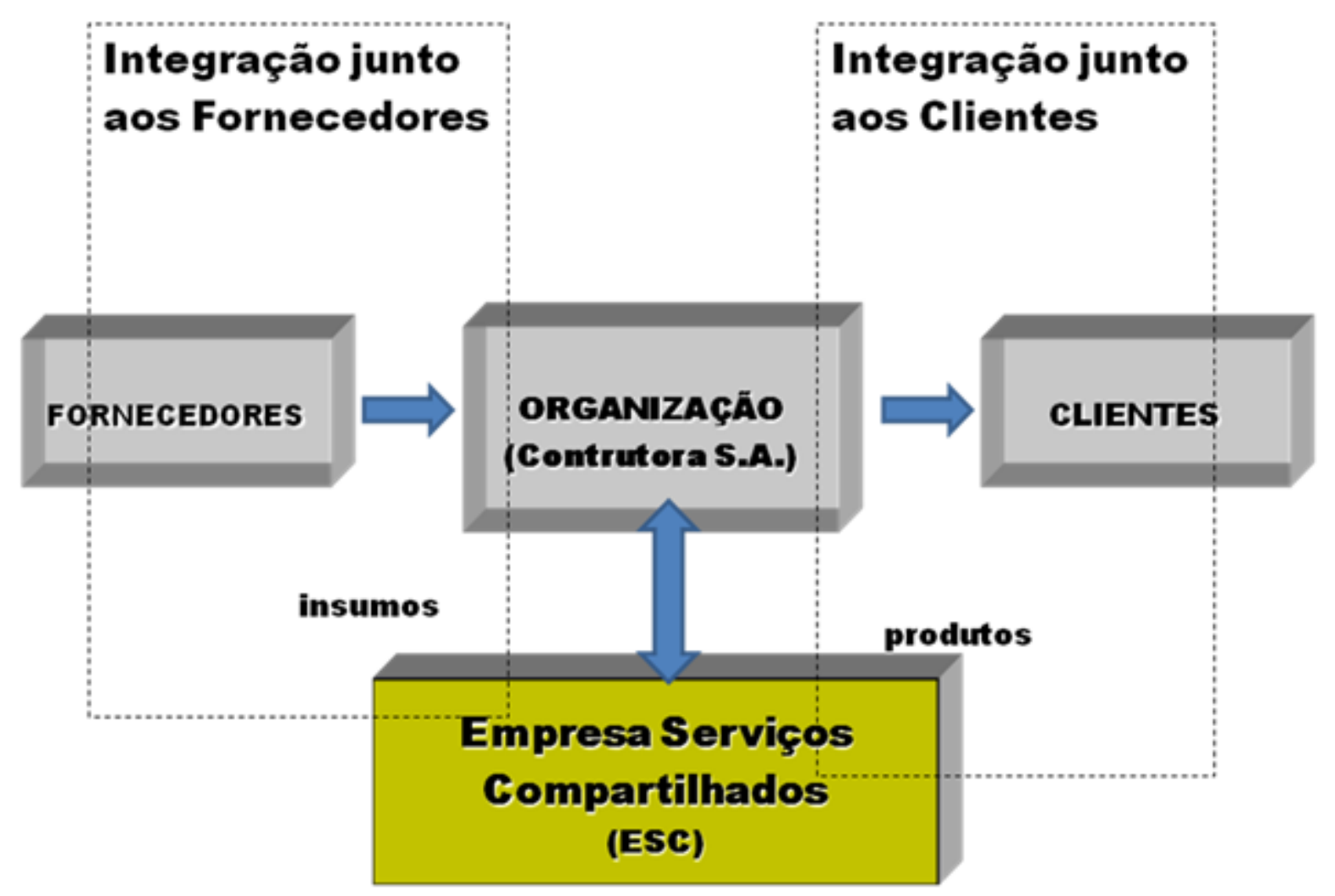

Tal representação evidenciou a visão simplificada da Construtora S.A., que foi implementada a partir de um conjunto de processos produtivos que transformavam os insumos em produtos (bens e/ou serviços).

Incorporando-se às entidades relevantes da organização (fornecedores, clientes e diferentes públicos), obteve-se o fluxo básico da organização, estruturado conforme modelo ilustrado na figura 02 .

E, internamente, foi adotado um formato organizacional que procurou identificar e segregar os processos produtivos dos processos de apoio (tópico 7.2 Reconfiguração por Processos da Construtora S.A.).

Esta definição levou em conta o ramo de negócios da organização (TACHIZAWA, 2010), de forma a subsidiar a delimitação dos processos em produtivos e estratégicos. Aliado a este fator, considerou-se a permanente interação com o mercado, para correlacionar os clientes, produtos/serviços e processos produtivos (TACHIZAWA; SCAICO, 2006).

A partir desta análise tornou-se possível estabelecer regras de gestão para subcontratar externamente as atividades inerentes aos processos não-estratégicos bem como aqueles processos considerados de apoio aos produtivos. 
Combinado a isto, considerou-se a utilização dos recursos humanos, agrupados em equipes de trabalho, as células dos processos, conjugada à aplicação dos recursos das tecnologias da informação - TI no contexto do ambiente de processos.

Nesse cenário, de estrutura horizontalizada, com fronteiras ampliadas e adoção de serviços compartilhados pelas empresas pertencentes ao pool de construtoras, foi possível aplicar uma abordagem de gestão estratégicas das TI, conforme evidenciado no tópico 7.3. Tecnologias da informação - TI.

Essa otimização na gestão estratégica dos recursos de TI foi decorrência da aplicação de um enfoque sistêmico, considerando uma análise de fora-para-dentro da organização (concepção da ESC) e do geral-para-o-particular (reconfiguração por processos da Construtora SA).

\subsection{Configuração de serviços compartilhados}

\subsubsection{Concepção do modelo de gestão}

Para o tipo de empresa de médio porte do setor econômico de construção civil, que é o caso da Construtora S/A, a estratégia foi calcada uma flexibilidade operacional que se apoiaria em um modelo organizacional centrado nas atividades essenciais, ao lado das atividades acessórias subcontratadas junto ao mercado. Esta foi a filosofia que deu origem a criação da ESC (vide Figura $02)$.

Figura 02: Horizontalização da cadeia produtiva

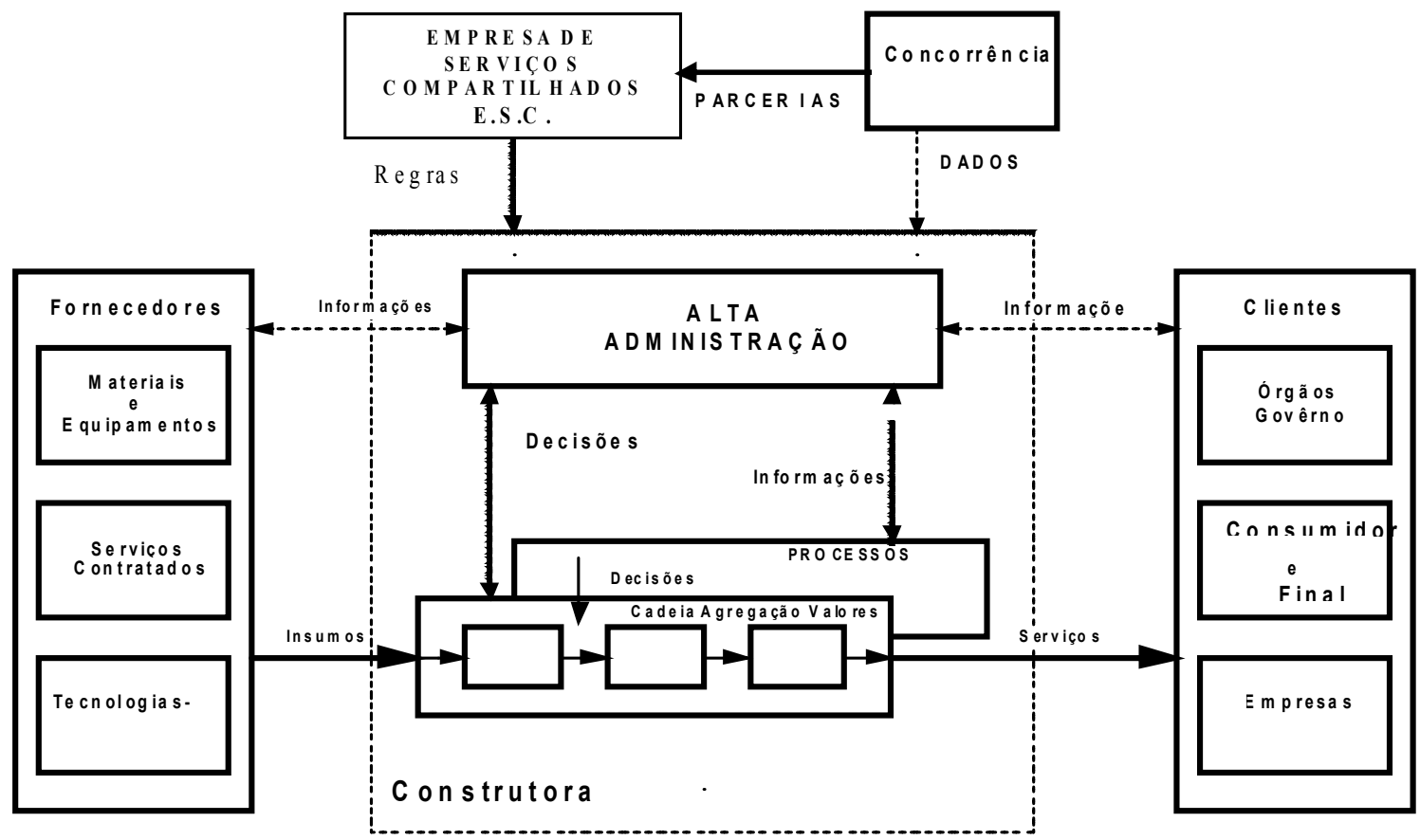


Estas atividades, consideradas acessórias para efeito do modelo de organização adotado, podem ser subentendidas como sendo aquelas relacionadas às interligações da pequena e média empresa do setor, com o mercado, tanto para-trás (fornecedores de serviços e insumos produtivos), como para-frente (clientes intermediários e finais).

Esses elementos estratégicos exigiram como pré-requisito que a organização estabelecesse uma interação permanente com o mercado, dentro dos contornos do modelo em torno de processos concebido para a ESC (vide figura 02).

Esta abordagem por processos, com a implementação da $E S C$ permitiu que as necessidades de informação de nível operacional da Construtora S.A. e das demais micro e pequenas empresas, integrantes do pool de construtoras fossem, sistemicamente, supridas pela mesma. Isso permitiu que as empresas concentrassem esforços em informações de nível estratégico para fins de implementação de suas tecnologias da informação.

\subsubsection{Parceria e ampliação das fronteiras organizacionais}

A Empresa de Serviços Compartilhados - ESC foi concebida como uma organização, criada com recursos de um pool de micro e pequenas empresas do ramo de construção civil habitacional.

Organizações (247 empresas), filiadas a Associação de Classe da Indústria da Construção, após passarem por fase conjuntural da economia extremamente difícil, resolveram reduzir seus custos operacionais constituindo uma entidade independente, cuja missão seria a prestação de serviços de apoio às empresas construtoras do pool. As empresas que constituíam o pool se caracterizavam por serem de pequeno e médio porte.

A ESC tinha por missão, a prestação de serviços de compras, de recursos humanos, de serviços gerais, de manutenção e conservação predial, de serviços financeiros e contábeis, e outros serviços correlatos.

No contexto econômico em que se inseria, vivenciava instabilidade e alta variabilidade de cenários em função da atuação da administração governamental, normalmente transitória e cíclica, o que tornava fundamental que qualquer estratégia competitiva a ser adotada pelas empresas do setor, levasse em conta a necessidade de manter alto grau de flexibilidade e adaptabilidade em seu processo de gestão.

Com essa expansão da cadeia produtiva junto a fornecedores, clientes e demais públicos de interesse, a organização tendia a ampliar, virtualmente, suas fronteiras, na medida em que sistemicamente sua atuação se fazia presente, internamente, às organizações que com ela interagiam. 


\subsubsection{Processos da empresa de serviços compartilhados - ESC}

A ESC foi constituída, formalmente, dentro deste contexto estratégico, como uma central que absorveria as atividades operacionais repassadas pelas empresas construtoras do pool. Esta entidade, juridicamente independente, atuava de forma conveniada com o Sindicato e com as empresas construtoras do pool.

Os serviços prestados pela ESC foram consolidados em: serviços jurídicos; serviços gerais e condominiais; serviços de manutenção e conservação predial; serviços contábeis; serviços financeiros de pagamentos e recebimentos; serviços de compras; serviços de folha de pagamento; assistência social e médica; e serviços de treinamento de pessoal.

\subsubsection{Identificação dos processos-chave}

Uma empresa de prestação de serviços como a ESC pode ter seus processos definidos através de resposta às questões, como quais são os: processos; as tarefas/atividades de cada processo; os fornecedores internos e/ou externos de cada processo; serviços por cada processo; são os clientes internos e/ou externos de cada processo.

A identificação dos processos-chave, que constituía a etapa preliminar da abordagem, a rigor se resumia em uma análise e classificação dos processos da organização visando: (a) definir os processos, considerados chave, que contribuem para o cumprimento da missão da organização ou de outros processos; (b) ordenar todos os processos, inclusive os processos-chave, em função do seu estágio de padronização. A partir das questões inerentes aos processos da $E S C$, os mesmos foram classificados em processos-chave e processos operacionais em uma primeira fase de análise. Identificou-se um conjunto de processos existentes em um total de 17.

Posteriormente ao inventário dos processos existentes, os mesmos foram analisados e hierarquizados, de forma colegiada com os gestores da Organização, com a aplicação dos respectivos critérios de avaliação.

Em avaliação conjunta com os gestores da Organização esses 17 processos, dentre eles os processos-chave, foram consolidados na análise explicitada no Quadro 1. 
Quadro 1. Critérios de avaliação de processos sistêmicos

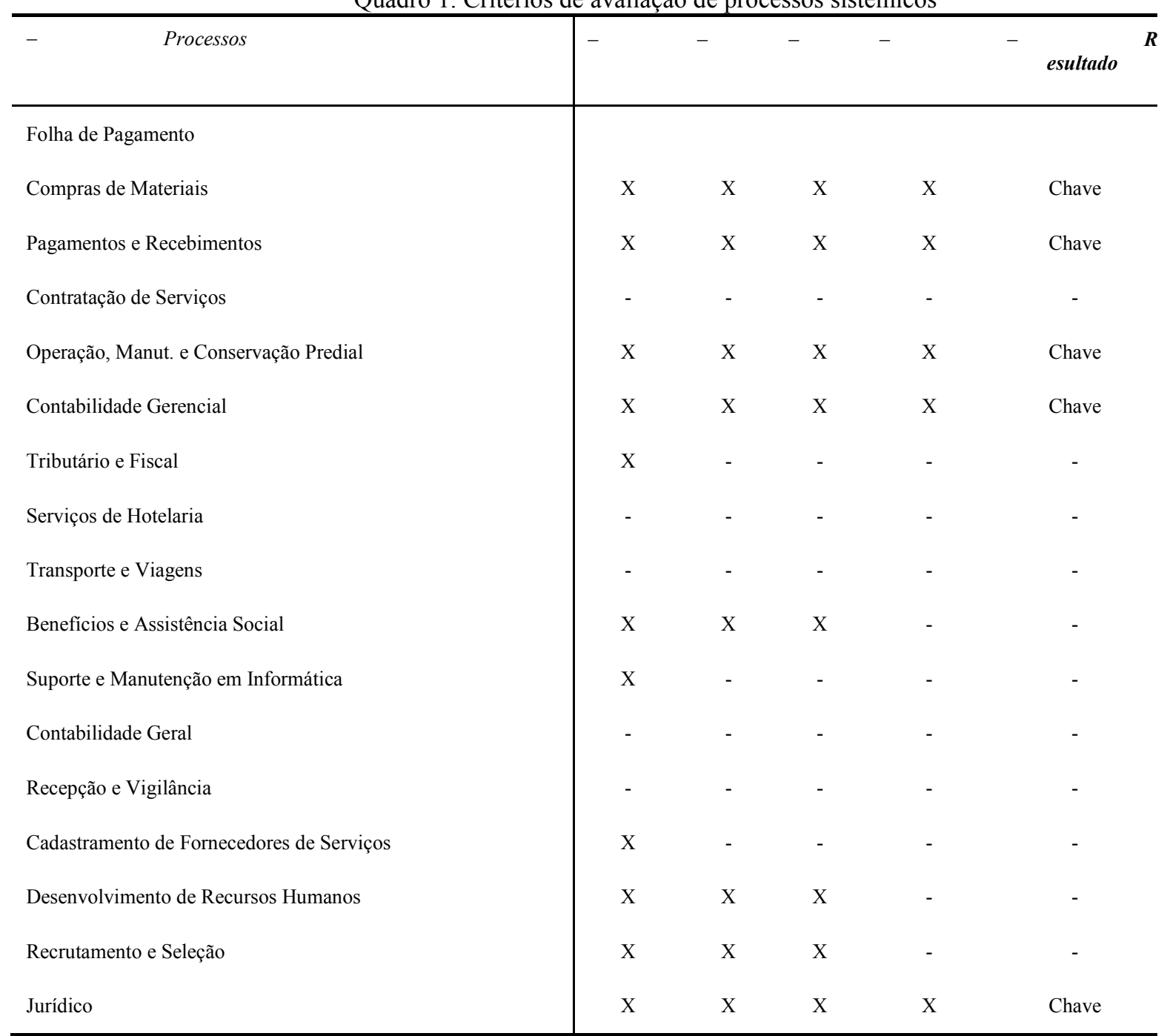

Legenda: (1) processos voltados ao atendimento a clientes; (2) processos com significativos volumes/valores envolvidos que possam afetar significativamente os resultados da organização; (3) grau de contribuição para o cumprimento dos objetivos dos clientes; (4) processos integradores de unidades organizacionais, ou seja, aqueles intersetoriais que unem diferentes tarefas/atividades, horizontalmente na estrutura hierárquica.

Através de tais resultados, e considerando a possibilidade de fusão de desenvolvimento de recursos humanos com recrutamento e seleção, obteve-se, portanto, os seguintes processos-chave: Compras de Materiais; Pagamentos e Recebimentos; Contabilidade Gerencial; Operação, Manutenção e Conservação Predial; Assistência Social e Benefícios; Desenvolvimento de Recursos Humanos e Recrutamento e Seleção de Pessoal; Jurídico. A fusão de processos tornou-se conveniente nos casos em que havia analogia, similaridade e complementaridade na natureza dos processos comparados. Tal situação, conjugada aos resultados obtidos pela aplicação dos quatro critérios, quando se obtém uma alta incidência de respostas favoráveis, definiu os demais processoschave. A identificação dos processos-chave definiu aquilo que é essencial aos negócios da organização e que, portanto, deviam ser mantidos na futura configuração organizacional. Os demais processos, que normalmente se caracterizavam como sendo processos de apoio, foram candidatos a serem repassados para terceiros, ou mesmo eliminados, após análise mais aprofundada. A aplicação de outros critérios de avaliação (5, 6 e 7) nos processos teve por finalidade estabelecer uma ordem 
de prioridade a ser seguida na fase de padronização destes processos, quais sejam:

5 verificou-se o atual estágio de evolução/estabilidade do processo sob análise, uma vez que mesmo que seja considerado de nível estratégico, o processo pode estar num nível de padronização satisfatório que dispensaria uma intervenção imediata. A recíproca também ocorreu; um determinado processo de nível operacional, cujo estágio de evolução precário, em que eventualmente se encontre, justifique uma definição de alta prioridade;

6 analisou-se o resultado da avaliação dos clientes externos quanto à qualidade dos serviços gerados pelos atuais processos do CSA, que pode ser um processo de nível estratégico, mas que se encontra em um nível satisfatório de atendimento às expectativas de seu mercado;

7 pressões externas ao ESC (exigências contingenciais): mudanças na legislação; normas corporativas; e afins.

- A aplicação de tais critérios, efetuada pelos Gestores para cada processo, levou em conta o nível de importância relativa (prioridade) para cada fator, utilizando-se da escala: ( 1 ) sem importância; ( 2 ) pouco importante; ( 3 ) importante; ( 4 ) muito importante. Esta providência foi feita através de planilha preenchida inicialmente de forma individual para uma posterior análise e consenso do grupo reunido, contendo os processos relacionados em ordem alfabética como linhas, e os critérios de avaliação como colunas. Feita a tabulação das respostas e a ordenação decrescente pelo somatório dos níveis atribuídos aos sete critérios para cada processo, obteve-se a seguinte priorização de processos:

01 - Operação, Manutenção e Conservação Predial; 02 - Compras de Materiais;

03 - Pagamentos e Recebimentos;

04 - Jurídico;

05 - Contabilidade Gerencial;

06 - Desenvolvimento de R.H.;

07 - Recrutamento e Seleção;

08 - Benefícios Assistência Social;

09 - Serviços de Hotelaria;

10 - Transporte e Viagens ;

11 - Tributário e Fiscal;

12 - Suporte em Informática;

13 - Contabilidade Geral;

14 - Recepção e Vigilância;

15 - Cadastramento Fornecedores Serviços;

16 - Contratação de Serviços;

17 - Folha de Pagamento.

Foram hierarquizados esses 17 processos e selecionados os sete primeiros, priorizados para efeito de racionalização e padronização. Os demais processos foram considerados não-prioritários em função da pontuação obtida, e foram considerados sérios candidatos à eliminação ou terceirização. Ou seja, as tarefas e atividades inerentes aos processos não-prioritários, dado que não contribuíam diretamente aos resultados da organização ou não representavam valores significativos, não necessitavam ser operacionalizados na própria empresa. A partir de tal constatação, tornou-se possível se concentrar apenas nos processos considerados prioritários, os processos-chave da 
organização, direcionando a sua total informatização. Estes resultados obtidos em termos de identificação da importância relativa dos processos da organização subsidiaram, também, a estruturação da $E S C$, conforme evidenciado a seguir.

\subsection{Organização da Empresa de Serviços Compartilhados - ESC}

Este novo enfoque (vide figura 04) permitiu que a ESC, fosse estruturada com modelo de gestão composto de cadeia produtiva compacta em termos de tamanho e de subcontratação externa de atividades terceirizáveis. Este formato de organização tendia a propiciar parcerias com micro e pequenas empresas que funcionariam em regime de subcontratação e fornecimento cativo à organização (TACHIZAWA; FARIA, 2004).

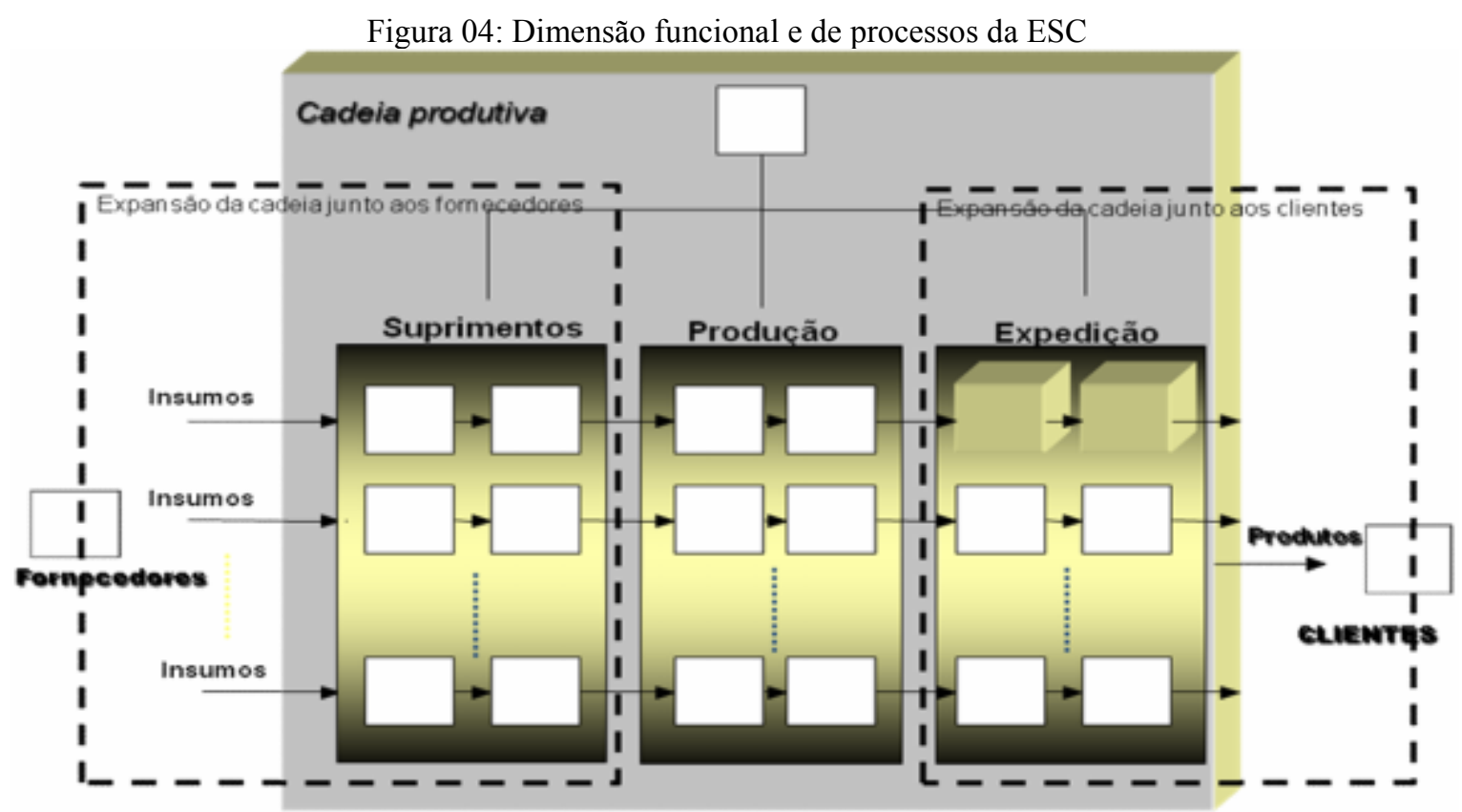

Foi o conceito adotado na constituição da ESC (vide Figura 04) que considerava a eliminação das barreiras físicas entre as empresas dando lugar a empresas virtualmente interligadas a organizações de grande porte. Redes informatizadas aproximam as empresas e criam condições para parcerias e alianças estratégicas, isso evita contratações de pessoal próprio. A ampliação virtual das fronteiras da organização propiciou um cenário em que:

a) o acesso às informações da organização fica, virtualmente, disponibilizado aos seus fornecedores, parceiros e agentes externos;

b) a interligação com os clientes da organização se torna benéfico para ambas as partes, fortalecendo a fidelidade e relacionamento de longo prazo;

c) a participação relativa das organizações de um mesmo setor se altera constantemente em 
função direta da adoção de tecnologias da informação como software de comunicação (internet, intranet e afins) e software de intercâmbio eletrônico de documentos e atividades empresariais, no plano inter-organizacional, tais como eBusiness, B2B (business to business), B2C (business to commerce) outras funções de comércio eletrônico equivalentes (GONÇALVES; RICCIO, 2009, ALBERTIN, 2010); e de redes informatizadas; a inovação introduzida por uma organização tende a provocar mudança no market share, afetando as demais organizações concorrentes;

d) a cooperação entre fornecedores concorrentes pode ocorrer em face da possibilidade de ganhos e benefícios comuns entre as mesmas (por exemplo, sistemas de reservas de hotéis, transações interbancárias eletrônicas, intercâmbio em rede de pesquisas, e afins);

e) a criação de parcerias e alianças entre organizações, propiciadas pela interligação virtual, permite a geração de novos produtos e serviços, sem a criação física de novas empresas ou mesmo de novos departamentos, diferentemente da era industrial, onde as organizações tinham necessidade de ser auto-suficientes por meio da integração vertical. Os novos tempos exigem da organização de grande porte um enfoque para a integração horizontal, passando a interagir com fornecedores e entidades externas na forma de parcerias e alianças estratégicas.

\subsection{Estruturação por processos na Construtora S.A.}

$\mathrm{Na}$ estruturação da Construtora S.A. por processos sistêmicos, além do regime de parceria com a ESC, procurou-se delinear os processos produtivos de forma segregada dos processos de apoio. Tal definição, além de subsidiar a adoção de esquemas de parcerias e terceirização, foi base para uma nova configuração organizacional, que em sua dimensão horizontal enfocou o relacionamento com os clientes como prioridade maior. Dada a implantação da padronização dos processos reestruturou-se a empresa, com a redefinição dos seus níveis hierárquicos. A estrutura organizacional verticalizada foi combinada com a gestão por processos e por equipes interfuncionais. A gestão por processos, diferentemente da administração funcional, coordena todas as tarefas e atividades inerentes ao(s) processo(s), sob a área de domínio, delimitada como hierarquicamente vinculada a cada Coordenação de Processos. Tal definição teve como ponto de partida a delimitação de todos os processos da organização e decorrente identificação dos processos-chave da organização.

Como resultado da implementação da organização por processos, pode-se obter uma estrutura plana e com menor numero de níveis hierárquicos, quando comparada com uma empresa do tipo funcional e verticalizada. A proposta de estrutura horizontalizada propiciou uma amplitude de controle maior, com a autoridade e responsabilidade exercitada em níveis mais baixos da Organização. Esta recomendação se apoiava, ainda, no princípio de alargamento das atividades empowerment - cuja característica é considerar que quem melhor entende uma dada tarefa é quem a 
executa, portanto, dar autonomia de decisão aos colaboradores internos foi fundamental (TACHIZAWA; FERREIRA; FORTUNA, 2005).

Equipes de trabalho flexíveis e polivalentes passaram a tomar parte diretamente das decisões, equipes estas constituídas na forma de célula, que por sua vez, no seu conjunto formavam os processos. Por célula entendia-se o sistema que reunia grupos de colaboradores responsáveis pela produção de serviços, com autonomia de decisão, onde cada um conhece todos os tipos de operação de sua célula.

A adoção do conceito de célula na reconfiguração proposta pressupunha, portanto, a formação de equipes ou células multidisciplinares, reunindo profissionais das mais diversificadas especialidades, com objetivos bem definidos e autonomia de trabalho.

Isso enfatizava a complementaridade de visões dos integrantes da célula e favorecia a cooperação, e onde as interações interdisciplinares propiciavam um repertório mais robusto de respostas aos desafios cada vez mais complexos da incessante necessidade de melhoria de desempenho e de qualidade.

Portanto, internamente a cada processo, as tarefas/atividades foram agrupadas, com o apoio das TI, segundo a lógica do processo sob estudo.

Sua composição observava um agrupamento das células (vide figuras 05 e 06) de forma a agrupar os elementos das equipes de trabalho:

- em células dispostas verticalmente, segundo um critério por cliente ou por produto;

\section{Figura 05: Estruturação verticalizada das células do processo}

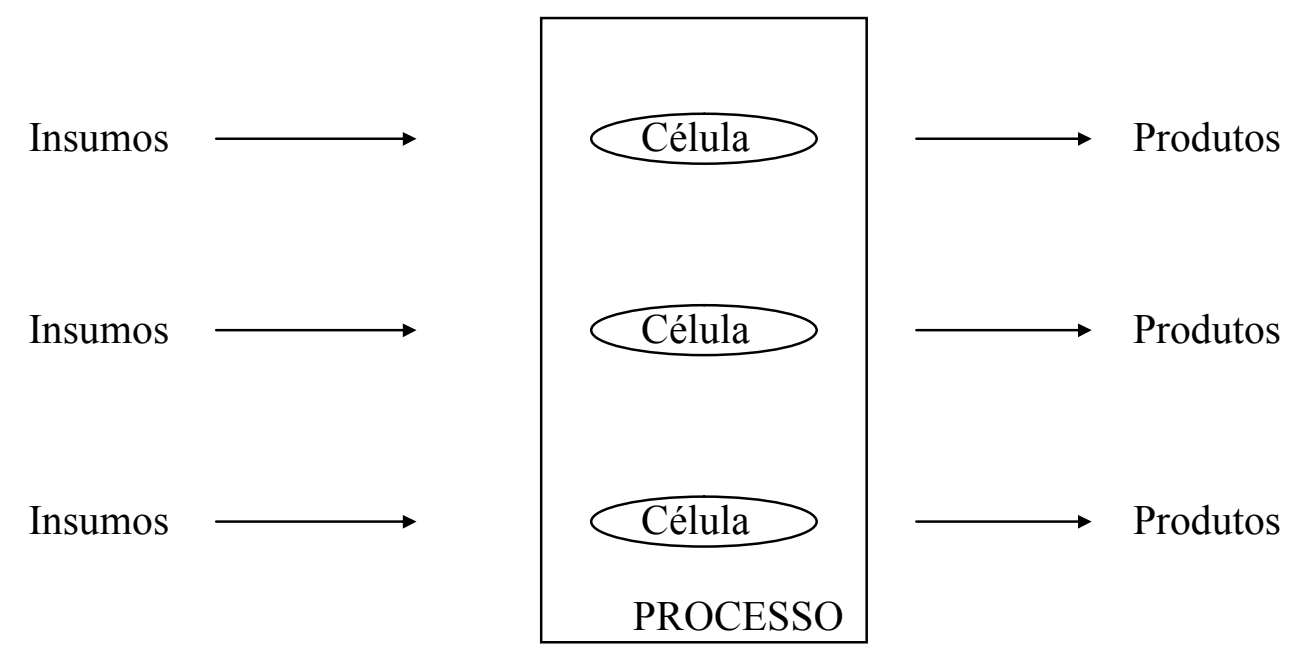

- em células dispostas horizontalmente em sequência lógica de ocorrência, segundo um critério por natureza, especialização ou modalidade. 


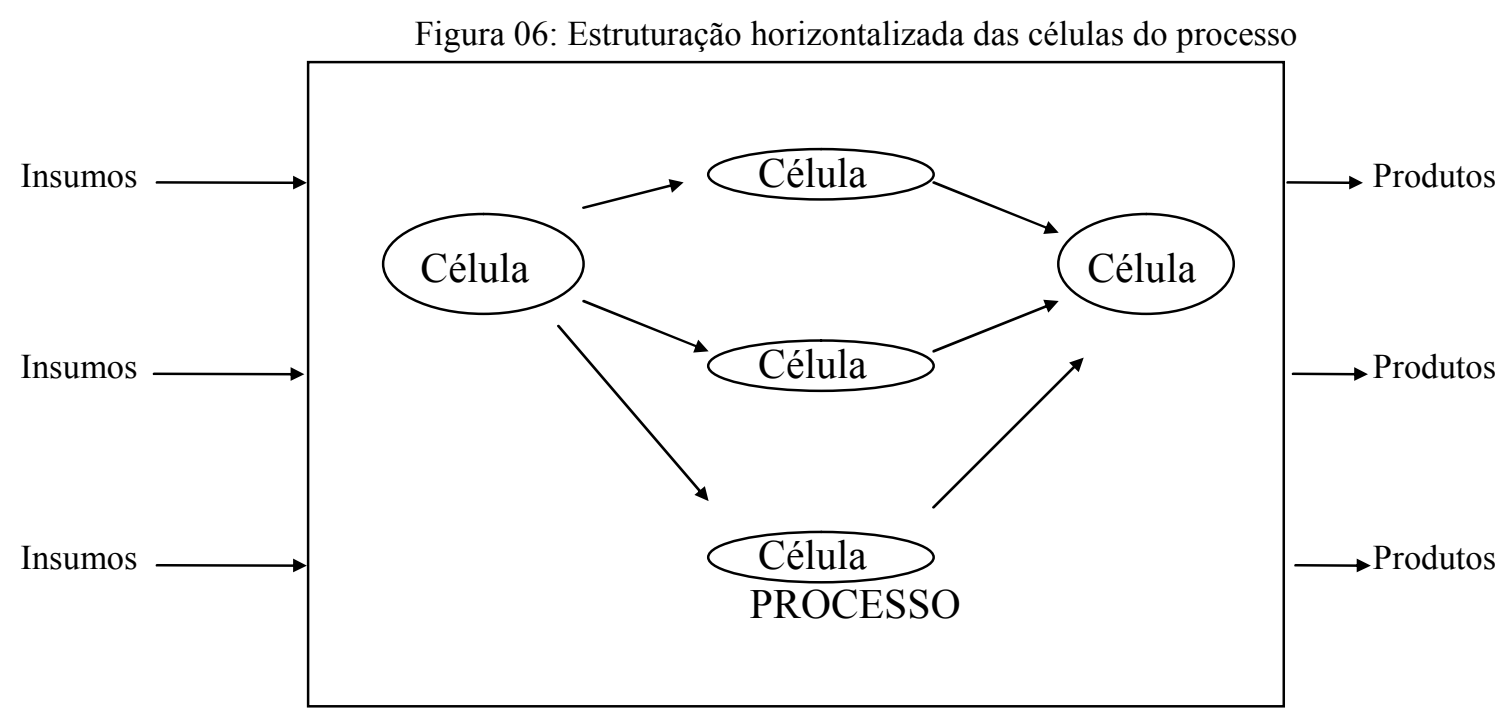

Nessa abordagem, foram agrupados processos correlatos e complementares entre si, em Coordenação de Processos (com Gestor dos processos de sua área de domínio). O desdobramento do processo em célula permitiu a redução da necessidade de processar informações (GALBRAITH, 1987) o que possibilitou um menor volume de investimentos em TI. Propunha-se visualizar a empresa além das fronteiras funcionais que compunham o organograma tradicional tendo em vista a explicitação do fluxo de processos da organização como um todo.

Na identificação e priorização dos processos puderam ser adotados critérios, como: a) tratarse de clientes externos à empresa; b) valores envolvidos no processo; c) grau de impacto sobre os clientes; d) natureza integradora do processo (inter-setorial); e) estágio de padronização do processo; f) pressões externas (à empresa) sobre o processo.

Os processos, sob a visão do cliente, puderam ser visualizados em termos de: processos produtivos e processos de apoio.

Esta forma de agrupamento dos processos da empresa foi feita sob a forma de como o cliente enxerga a organização. Os processos que geravam produtos a órgãos-cliente foram considerados como produtivos.

Por processos de apoio, entendiam-se aqueles que proporcionavam suporte à produção e ao fornecimento de produtos. Esta abordagem de processos resultou em significativos impactos no uso das TI, conforme explicitado no tópico 7.3.

\subsection{Efeitos nas tecnologias da informação}

A utilização da configuração por processos possibilitou que o planejamento da informatização da empresa, fosse priorizada nos processos-chave.

Apesar do significativo volume de processos sistêmicos na Construtora S.A. e nas empresas pertencentes ao pool (ESC), o simples fato de serem enfocados apenas os sistemas diretamente 
relacionados aos processos-chave, possibilitou que fosse enfatizada, essencialmente, TI que de fato contribuía para efetivação das estratégias corporativas e, portanto, dos negócios da empresa.

Nessa implementação de TI alicerçada na configuração por processos, considerou-se a:

- parceria das construtoras na forma de um pool, possibilitou que sistemas de informação de nível operacional (contabilidade, folha de pagamento, contas a pagar, compras, e sistemas correlatos) fossem centralizados e compartilhados entre as empresas consorciadas, com significativa economia de escala (central de serviços de informática);

- otimização da gestão estratégica da informação, com a centralização de todas suas funções em um único segmento organizacional. Isso possibilitou mudanças no perfil das atividades de desenvolvimento de software, observando o uso de ferramentas que permitiam a obtenção de sistemas com características amigáveis, não-rígidas, de desenvolvimento rápido e objetivando soluções localizadas;

- incorporação da visão do negócio aos sistemas de informação, apoiando fornecedores, clientes e gestores dos processos-chave no uso estratégico das informações;

- descentralização do uso das TI, com a disponibilização de dados para acesso, trazendo ao usuário a capacidade de manuseio e geração da sua própria informação, com consultas flexíveis e amigáveis;

- modelagem dos sistemas de informação (ALBERTIN, 2009) para atenderem as características dos processos estratégicos provendo, inclusive, o compartilhamento de tarefas ao longo da cadeia de agregação de valores da empresa, incluindo, ERP - Enterprise Resource Planning (GONÇALVES; RICCIO, 2009) software de comunicação (internet, intranet e afins) e software de intercâmbio eletrônico de documentos e atividades empresariais, no plano interorganizacional (eBusiness, B2B, B2C e demais funções de comércio eletrônico equivalentes (ALBERTIN, 2010);

- implementação de TI inovadoras, prioritariamente, para os processos-chave, baseadas em sistemas abertos, arquitetura cliente/servidor, banco de dados relacionais distribuídos, ferramentas de aumento de produtividade, com características amigáveis para os softwares desenvolvidos.

A dimensão de processos obtida pela compatibilização das visões, funcional e horizontal, permitiu identificar as efetivas oportunidades de implementação de tecnologias da informação que contribuíam para a melhoria dos resultados corporativos (GONÇALVES; RICCIO, 2009).

A simples configuração por processos permitiu visualizar as necessidades de comunicação, com transparência, com os diferentes públicos da organização. Por exemplo, no processo de “contabilidade gerencial" priorizado como processo-chave na empresa, objeto do estudo de caso, adotou-se o conceito de transparência com responsabilidade social junto à comunidade, através da divulgação de balanços socioambientais (TACHIZAWA, 2010). 
Esta visão sistêmica, enfim, representou uma perspectiva diferente da tradicional estrutura verticalizada, permitindo:

- incluir os elementos que normalmente faltam nos modelos de representação funcional, na forma de estrutura organizacional clássica, quais sejam: o cliente; o produto e o fluxo de trabalho;

- visualizar como o trabalho é realmente feito por processos, que perpassam horizontalmente as fronteiras funcionais;

- evidenciar os relacionamentos internos entre cliente-fornecedor, por meio dos quais são gerados produtos e serviços.

De fato, essa dimensão horizontalizada da organização possibilitou a visualização de significativas oportunidades de melhoria no desempenho, que estão nas interfaces funcionais; aqueles pontos críticos do fluxo de produtos e serviços entre unidades organizacionais. Essa melhoria na performance corporativa se apoiou na padronização de processos agrupados na Empresa de Serviços Compartilhados - ESC, principalmente, aqueles estratégicos, que alavancavam a competitividade empresarial, viabilizada pela:

- estabilização dos processos sistêmicos;

- qualidade na organização formal com clara definição de responsabilidade e autoridade;

- acumulo do conhecimento tecnológico possibilitando a gestão do conhecimento para permitir melhoria contínua e aumento da produtividade;

- abordagem estratégica para implementação dos recursos de tecnologias da informação.

Esta abordagem por processos permitiu ampliar as fronteiras da organização, objeto do estudo de caso, criando um cenário em que:

a) o acesso às informações da organização ficasse disponibilizado aos seus parceiros e agentes externos;

b) a interligação com os clientes da organização se tornaria benéfica para ambas as partes, fortalecendo a fidelidade e relacionamento de longo prazo;

c) a cooperação entre organizações fornecedoras de insumos podia ocorrer face às possibilidades de ganhos e benefícios comuns entre as mesmas;

d) a criação de parcerias e alianças estratégicas entre as organizações concorrentes e a Construtora S.A., entre elas a criação do pool de prestação de serviços comuns (Empresa de Serviços Compartilhados - ESC), foi viabilizada para fins de ganhos de economia de escala e produtividade na implementação das TI.

De fato, este ambiente de processos possibilitou a horizontalização da estrutura na forma de um organograma com menor número de níveis hierárquicos, propício à redução da necessidade de processar informações. Isso se contrapunha à estrutura verticalizada, ou funcional, com maior número de níveis hierárquicos (aumento da necessidade de processar informações). 
Como resultado da migração do ambiente de estrutura funcional para o ambiente de processos, obteve-se uma menor necessidade de investimentos em tecnologias da informação. Isso se explicava pelo fato de que quanto maior o número de níveis hierárquicos, maior a exigência de sistemas de informação para transmissão de informação, verticalmente entre os níveis da pirâmide organizacional.

A estrutura horizontalizada, em contrapartida, exigia poucos requisitos de informação para fluir verticalmente. Ou seja, o resultado final obtido foi um menor fluxo de informação vertical para conexão dos diferentes níveis hierárquicos e uma maior evidenciação das interfaces entre os segmentos organizacionais internos a cada processo sistêmico.

Isso possibilitou um ganho quantitativo de um menor numero de sistemas de informação e ao mesmo tempo em que podia ocorrer um ganho qualitativo pela otimização de cada processo sistêmico em decorrência de que regras de decisão a serem internalizadas em cada sistema de informação se evidenciavam nas interligações interna a cada processo e nas interfaces entre os mesmos processos sistêmicos.

\section{Conclusões}

Este trabalho apresentou um modelo de gestão em rede de serviços compartilhados em tecnologias da informação. É uma proposta de análise expandida da cadeia produtiva, ampliando-a em direção a fornecedores, clientes, concorrentes e demais instituições do mercado.

Evidências obtidas pela aplicação do modelo em uma empresa do setor de construção civil, objeto do estudo, sinalizaram que o constructo, que transcende a mera análise individual de uma organização, permite agrupar empresas concorrentes e complementares (fornecedores e clientes intermediários), em regime de parceria, na forma de um pool de organizações congêneres.

Tal modelo de gestão possibilitou que houvesse economia de escala na implementação de tecnologias da informação, de nível operacional e estratégico, na medida em que as mesmas foram centralizadas em uma central de serviços de informática para atender as construtoras pertencentes ao pool de organizações do setor.

A implantação do constructo permitiu que a organização pudesse: a) concentrar esforços nas atividades estreitamente vinculadas à missão da organização; b) repassar para terceiros, em regime de subcontratação, as atividades que não agregavam valor aos serviços prestados pela construtora; c) estruturação das atividades em torno de processos de forma a racionalizar o fluxo de decisões e informações (entre processos sistêmicos internos) e de maneira inter-organizacional (junto a fornecedores, clientes e entidades externas). 
Com isso foi possível identificar as necessidades de tecnologias da informação, diretamente relacionadas com os objetivos corporativos e estratégias de negócios da organização. A migração do ambiente de estrutura funcional para o ambiente de processos possibilitou uma menor necessidade de investimentos em tecnologias da informação. Isso porque quanto maior o número de níveis hierárquicos, maior a exigência de sistemas de informação para transmissão de informação, verticalmente entre os níveis da pirâmide organizacional.

A estrutura horizontalizada, em contrapartida, exigia poucos requisitos de informação para fluir verticalmente, com menor fluxo de informação vertical para conexão dos diferentes níveis hierárquicos.

Obteve-se ganho quantitativo de um menor numero de sistemas de informação e ao mesmo tempo em que ocorria um ganho qualitativo pela otimização de cada processo sistêmico em decorrência de que regras de decisão foram internalizadas em cada sistema de informação de forma a racionalizar as interligações interna a cada processo e nas interfaces entre os mesmos processos sistêmicos. Sugere-se que estudos similares sejam realizados em outros setores econômicos uma vez que o presente trabalho enfocou apenas o segmento de construção civil.

\begin{abstract}
The paper presents a management model of a network of information tecnologies shared services. Adopted the methodology of case study and evidence was obtained from the application of the model in a construction company. The construct allowed to group companies under the collaborative work. In the case analyzed implemented a partnership basis in the form of a pool of organizations to create a central information technology services. Among the results achieved by the adoption of the proposed model include the sharing of common services and achieving economies of scale in deploying information technology in the organization.
\end{abstract}

Key-words: extended supply chain; information tecnologies shared services; management model in network; decisions hierarquization.

\title{
Referências
}

ALBERTIN, A. L. Comércio eletrônico: modelo, aspectos e contribuições de sua aplicação. $6^{\mathrm{a}}$. edição. São Paulo: Atlas, 2010.

ALBERTIN, A. L. Administração de informática: funções e fatores críticos de sucesso. $6^{\text {a }}$. edição. São Paulo: Atlas, 2009.

EXAME. Publicação melhores \& maiores. Revista Exame. São Paulo: Abril, 2010.

GALBRAITH, J. Designing complex organizations. Reading, MA: Addison-Wesley. 1973.

GIL, A. C. Métodos e técnicas de pesquisa social. São Paulo: Atlas, 1987.

GONÇALVES, R. C. M. G.; RICCIO, E. L. Sistemas de informação: ênfase em controladoria e contabilidade. São Paulo: Atlas, 2009.

GOREY, R. M.; DOBAT, D. R. Managing in the knowledge. The systems thinker. Waltham, v.7, n.8, oct. 1996.

MintzBerG, H., AHLSTRAND B., LAMPEL, J. Safári de Estratégia. Porto Alegre: Bookman, 2000. 
MORGAN, G. Imagens da organização. Editora Atlas. São Paulo. 1996.

PRAHALAD, C. K.; HAMEL, G. The core competence of the corporation - HBR, May-June, 1990.

PORTER, M. E. Competição. Rio de Janeiro: Campus, 1998.

SELLTIZ, C. et al. Métodos de pesquisa nas relações sociais. São Paulo: Herder, 1987.

TACHIZAWA, T. Gestão ambiental e responsabilidade social corporativa: estratégias de negócios focadas na realidade brasileira. $6^{\text {a }}$. edição revista e ampliada. São Paulo: Atlas, 2010.

TACHIZAWA, T.; SCAICO, O. Organização flexível: qualidade na gestão por processos. $2^{\mathrm{a}}$. edição revista e ampliada. São Paulo: Atlas, 2006.

TACHIZAWA, T., FERREIRA, V. C. P.; FORTUNA, A. A. M. Gestão com pessoas: uma abordagem aplicada às estratégias de negócios. 4ª edição revista e ampliada. Rio de Janeiro: Fundação Getulio Vargas, 2005.

TACHIZAWA, T. e FARIA, M. S. Criação de novos negócios: gestão de micro e pequenas empresas. $2^{\mathrm{a}}$. edição revista e ampliada. Rio de Janeiro: Fundação Getulio Vargas, 2004.

TAPSCOTT, D. Economia digital. São Paulo: Pearson Education Makron Books.. 1999.

YIN, R. K. Estudo de caso: planejamento e métodos. Porto Alegre: Bookman, 2001.

\section{Dados dos autores:}

Nome completo: TAKESHY TACHIZAWA

Filiação institucional: Faculdade Campo Limpo Paulista - FACCAMP

Departamento: Programa de Mestrado em Administração

Função ou cargo ocupado: Professor Pesquisador

Endereço completo para correspondência:

Rua Guatemala, 167- Jardim América

13.231-230 - Campo Limpo Paulista - SP

FONE: (12) 9105-0988 E FAX: (11) 4812-9400

e-mail: usptakes@uol.com.br

Nome completo: HAMILTON POZO

Filiação institucional: Faculdade Campo Limpo Paulista - FACCAMP

Departamento: Programa de Mestrado em Administração

Função ou cargo ocupado: Professor Pesquisador

Endereço completo para correspondência:

Rua Guatemala, 167- Jardim América

13.231-230 - Campo Limpo Paulista - SP

FONE: (12) 9105-0988 E FAX: (11) 4812-9400 
e-mail:hprbrazil@hotmail.com

Recebido para publicação em: 26/10/2010

Aceito para publicação em: 15/11/2010 